\title{
Çeliklerin korozyonuna boraksın etkisi
}

\author{
Gülden Asan ${ }^{1, *}$, Abdurrahman Asan ${ }^{2}$ \\ ${ }^{1}$ Hitit Üniversitesi, Teknik Bilimler Meslek Yüksekokulu, Çorum, 19030, Türkiye \\ ORCID orcid.org/0000-0002-6075-159X \\ ${ }^{2}$ Hitit Üniversitesi, Mühendislik Fakültesi, Kimya Mühendisliği Bölümü, Çorum, 19030, Türkiye \\ ORCID orcid.org/0000-0002-1010-3981
}

\section{MAKALE BILGISi}

Makale Geçmişi:

İlk gönderi 1 Mart 2021

Kabul 8 Ağustos 2021

Online 30 Eylül 2021

Araştırma Makalesi

DOI: 10.30728/boron.889110

Anahtar kelimeler:

Boraks

Çelik

Korozyon

Tafel polarizasyon metodu

\section{ÖZET}

Bu çalışmada Ç 1010, Ç 304 ve Ç 316 çeliklerin korozyonuna boraksın $\left(\mathrm{Na}_{2} \mathrm{~B}_{4} \mathrm{O}_{7}\right)$ etkisi araştırılmıştır. Bu amaçla farklı derişimlerde $(0,0125 \mathrm{M}, 0,025 \mathrm{M}, 0,050 \mathrm{M}$ ve 0,100 M) borakslı çözeltiler hazırlanmıştır. Çeliklerin bu ortamdaki elektrokimyasal davranışını belirlemek için Dönüşümlü Voltametri (CV) tekniği, korozyon hızlarını ölçmek için ise Tafel Polarizasyon Yöntemi uygulanmıştır. Deneyler sonucunda boraks derişiminin artması ile her üç çelikte korozyon hızının azaldığı ve korozyon potansiyelinin arttığı tespit edilmiştir. En yüksek boraks derişiminde en düşük korozyon hızı Ç 316 çeliğinde belirlenmiştir. Ç 1010, Ç 304 ve Ç 316 çeliklerin 0,100 M boraks derişiminde korozyon hızları sırasıyla; 0,251, 0,132 ve 0,071 mm/yıl olarak ölçülmüştür. Boraks anodik inhibitör davranışı göstererek çelikleri korozyondan korumuştur. Çeliklerin borakslı çözeltilerde güvenle kullanılabileceği sonucuna varılmıştır.

\section{The effect of borax on corrosion of low carbon steels}

\section{ARTICLE INFO}

\section{Article History:}

Received March 1, 2021

Accepted August 8, 2021

Available online September 30, 2021

Research Article

DOI: $10.30728 /$ boron. 889110

\section{Keywords:}

Borax

Steel

Corrosion

Tafel polarization method

\section{ABSTRACT}

In this study, the effect of borax $\left(\mathrm{Na}_{2} \mathrm{~B}_{4} \mathrm{O}_{7}\right)$ on the corrosion of Ç 1010, Ç 304 and Ç 316 steels was investigated. For this purpose, solutions with borax at different concentrations $(0.0125 \mathrm{M}, 0.025 \mathrm{M}, 0.050 \mathrm{M}$ and $0.100 \mathrm{M})$ were prepared. Cycling Voltammetry (CV) technique was used to determine the electrochemical behavior of steels in this environment, and Tafel Polarization Method was used to measure corrosion rates. As a result of the experiments, it was determined that the corrosion rate decreased and the corrosion potential increased in all three steels with increasing borax concentrations. Lowest corrosion rate at higest borax concentration was obtained from Ç 316. Corrosion rates of Ç 1010, Ç 304 and Ç 316 steels at 0,100 M borax concentration have been measured respectively as $0.251,0.132$ and $0.071 \mathrm{~mm} /$ year. Borax protected steels from corrosion by showing anodic inhibitory behaviour. It is concluded that the steels can be used safely in borax solutions.

\section{Giriş (Introduction)}

Korozyon, gelişmiş ve gelişmekte olan ülkelerde büyük ekonomik ve güvenlik zararlarına neden olan evrensel bir sorundur. Korozyon, ekonomik ve güvenlik kayıplarının yanı sıra, zehirli kimyasalların ve solventlerin paslanmış metal ekipmanlardan sızması nedeniyle çevre sorunlarına da neden olur [1,2]. Çelikler, yüksek mekanik güç ve maliyet etkinliği nedeniyle en yaygın olarak inşaat ve yapı malzemeleri olarak kullanılmaktadır. Demir alaşımları, petrol ve gaz endüstrilerinde depolama tankı, işleme ekipmanları ve nakliye boru hatları olarak yaygın bir şekilde kullanılmaktadır. Malzeme kayıplarını azaltmak için korozyona karşı birçok yöntem uygulanmakla birlikte, organik bileşiklerin kullanımı, etkili ve kolay sentezleri, yüksek inhibisyon etkinliği ve maliyet etkinliği nedeniyle en yaygın ve en sık olanıdır. Genel olarak organik bileşikler, metal ve çevre (elektrolit) ara yüzünde koruyucu bir film oluşturarak korozyonu etkili bir şekilde inhibe ederler [3].

Ülkemizde bol miktarda bulunan bor, ekonomik olması ve stratejik olması nedeniyle birçok endüstride kullanım alanı bulmuştur. Bor, tepkimelerde katalizör [4], 
Tablo 1. Çelik malzemelerin kimyasal bileşimleri (Chemical compositions of steel materials).

\begin{tabular}{lccccccccc}
\hline & $\mathbf{C}$ & $\mathbf{M n}$ & $\mathbf{S i}$ & $\mathbf{P}$ & $\mathbf{S}$ & $\mathbf{C r}$ & $\mathbf{N i}$ & $\mathbf{M o}$ & $\mathbf{C u}$ \\
\hline Ç 1010 & 0,07 & 0,55 & 0,01 & $<0,01$ & $<0,01$ & $<0,01$ & 0,11 & 0,01 & 0,09 \\
Ç 304 & 0,07 & 1,91 & 0,77 & 0,047 & 0,03 & 18,25 & 8,20 & 0,08 & 0,25 \\
Ç 316 & 0,05 & 1,22 & 0,45 & 0,40 & 0,02 & 16,10 & 10,09 & 2,01 & 0,42 \\
\hline
\end{tabular}

nükleer teknolojide, yakıt olarak roket motorlarında, ısıya dayanıklı polimerlerde, kimyasal termokimyasal depolamada [5], cam, ilaç, boyar madde, kozmetik, alev geciktiricilerde, gıda koruyucularda, hafif antiseptiklerde, seramik ve refrakter gibi ısıya dayanımlı malzeme üretiminde, yüksek kalitede çelik, sabun, deterjan, antifriz, dezenfektan ve gübre üretimlerinde kullanılmaktadır [6,7]. Son zamanlarda yapılan bir araştırmada çelik yüzeyinde oluşturulan Ni-B kaplamaların, herhangi bir yağlayıcı takviye elemanı kullanılmadan aşınma ortamına dayanıklı olduğunu göstermiştir [8]. Korozyona karşı inhibitör olarak kullanımı ile ilgili çok sınırlı sayıda çalışma yapılmıştır $[9,10]$.

Metalleri korozyondan korumak için; metal kaplama, ortamı değiştirme, katodik koruma, anodik koruma, metali değiştirme vb. birçok yöntem kullanılmaktadır. Günümüz endüstrisinde çeliklerin çok yaygın kullanımı vardır. Ancak korozif ortamlarda özellikle asidik ve klorülü ortamlarda korozyona uğrarlar[11]. Çeliklerin korozyonunu önlemek için çözeltilere katılan nitritler, kromatlar ve fosfatlar gibi anodik inhibitörler çevreye olan toksik etkisi nedeniyle birçok ülkede kullanımları kısıtlanmış veya yasaklanmıştır [12-14]. Bu nedenle son zamanlarda daha çevreci metal tuzlarının inhibitör olarak kullanımı için birçok çalışma yapılmaktadır [15-17]. İnhibitörler, metal yüzeyinde adsorplanır veya metalleri (çelik, alüminyum, titanyum) pasifleştirerek ya da çözelti ortamındaki hidrojenin indirgenmesini önleyerek korozyonu önlerler $[18,19]$. Korozyonun önlenmesinde inhibitörün molekül yapısı kadar çözeltinin bileşimi ve metal yüzeyi de oldukça önemlidir $[20,21]$.

Bor bileşiklerin üretim sürecinde büyük oranda düşük karbonlu çelikler kullanılmaktadır. Ayrıca evlerde ve sanayide kullanılan temizlik maddelerin bileşiminde boraks yer almaktadır. Özellikle de çamaşır ve bulaşık makinalarında kullanılan deterjan bileşiminde bulunan boraksın makine aksamının korozyonuna ne kadar etki yaptığı konusunda daha önce bir çalışma yapılmadığı bilinmemektedir. Bu çalışma, bu amaca yönelik olarak boraksın, bor bileşiklerinin üretimi sürecinde kullanılan düşük karbonlu çelikten imal edilen ekipmanlara ve üretim sonrasında boraks ve boraks içeren kimyasalların kullanıldığı çelik malzemelere olan inhibitör etkisini tespit etmek için yapılmıştır.

\section{Malzemeler ve Yöntemler (Materials and Met- hods)}

Deneylerde, 250 ml'lik üç boyunlu korozyon hücresi kullanılmıştır. Çözeltiler deiyonize su içinde boraks çözülerek hazırlanmıştır. Kimyasal bileşimi Tablo 1'de verilen çalışma elektrotları, çelikler polyester reçineye gömülmüş ve $1 \mathrm{~cm}^{2}$ lik yüzey alanı çözeltiyle temas edecek şekilde açıkta bırakılacak şekilde hazırlanmıştır. Her deneyden önce çalışma elektrotunun yüzeyi su altında 4000 meshlik zımpara kâğıdı ile parlatıldıktan sonra saf su ile yıkanmıştır. Yağ ve kirlerden arındırmak için de etanolden geçirilmiştir. Karşı elektrot olarak $1 \mathrm{~cm}^{2}$ lik yüzey alanına sahip platin levha kullanılmıştır. Potansiyel ölçümleri için referans elektrot olarak da doygun kalomel elektrot (DKE) kullanılmıştır. Ölçülen potansiyeller bu elektroda göre verilmiştir. Tafel polarizasyon ölçümleri, bilgisayar kontrollü İvium Technologies De Regent 1785611 HW Eindhoven model Potansiyostat/Galvanostat cihazı ile elde edilmiştir.

Çeliklerin elektrokimyasal davranışını belirlemek amaclyla elde edilen dönüşümlü voltamogramlar, en derişik ortam olan 0,100 M borakslı çözeltilerde elde edilmiştir. Dönüşümlü Voltametri tekniği, $-1,50 \mathrm{~V}$ ile $+1,00 \mathrm{~V}$ aralığında $0,2 \mathrm{~V}$ tarama hızı ile uygulanmıştır. Korozyon hızının belirlenmesi için Tafel Polarizasyon yöntemi uygulanmıştır [22]. Bu amaçla; $0,0125 \mathrm{M}, 0,025 \mathrm{M}$, $0,050 \mathrm{M}$ ve $0,100 \mathrm{M}$ boraks içeren çözeltilerde, $-2,00 \mathrm{~V}$ ile $0,20 \mathrm{~V}$ potansiyel aralığında $0,002 \mathrm{~V} / \mathrm{s}$ tarama hızı ile çeliklerin polarizasyon eğrileri elde edilmiştir.

\section{Sonuçlar ve Tartışma (Results and Discussion)}

Çeliklerin elektrokimyasal davranışlarının belirlenmesi amacıyla boraks derişiminin en fazla olduğu $0,100 \mathrm{M}$ da Dönüşümlü Voltamogramları alındı. Şekil 1 de Ç 1010 çeliğin bu ortamdaki eğrisi görülmektedir. Ç 1010 çeliğinin ileri yöndeki anodik taramasında ileri yöndeki taramada -1,0 civarında anodik akımın başladığı ve

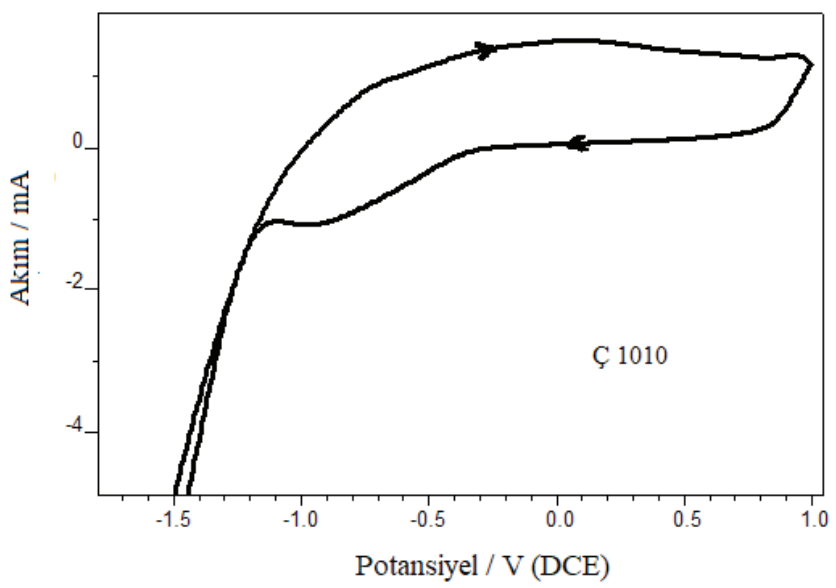

Şekil 1. Ç 1010 çeliğin 0,100 M boraks içeren çözeltideki dönüşümlü voltamogram (Cyclic voltammogram of Ç 1010 steel in solution containing $0.100 \mathrm{M}$ borax). 
$1,0 \mathrm{~V}$ a kadar pasifliğini koruduğu görülmektedir. Anodik akımın en fazla yaklaşık olarak $0,0 \mathrm{~V}$ da $1,5 \mathrm{~mA}$ olduğu anlaşılmaktadır. Geri yöndeki katodik taramada ise korozyon akımının azaldığı ve çukurcuk korozyonunun oluşmadığı anlaşılmaktadır [23].

Şekil 2 ve Şekil 3'de Ç 304 ve Ç 316 çeliklerin, $-0,5 \mathrm{~V}$ ve 0,8 V'da iki pasifleşme pikinin oluştuğu görülmektedir. Ancak Şekil 1'de verilen Ç 1010 çeliğinde bu pikler belirgin değildir. Birinci pik oluşumunda $\mathrm{Fe} \rightarrow \mathrm{Fe}^{2+}+2$ $\mathrm{e}^{-}$reaksiyonu ile $\mathrm{Fe}, \mathrm{Fe}^{2+}$ iyonlarına, ikinci pik oluşumunda $\mathrm{Fe} \rightarrow \mathrm{Fe}^{3+}+3$ e- reaksiyonu ile $\mathrm{Fe}, \mathrm{Fe}^{3+}$ iyonlarına ayrışmaktadır. Pasifleşmeye ise alaşım içindeki krom ve nikelin etkisi olduğu bilinmektedir [24]. Ç 1010 çeliğinde En yüksek anodik akım 1,5 mA olarak oluşurken, Ç 304 çeliğinde yaklaşık 1,0 mA olarak oluşmuştur. Ç 316 çeliğinde ise en yüksek potansiyelde $(1,0$ V) dahi akım 0,6 mA olarak okunmaktadır (Şekil 3). Üç çelik için geri yöndeki akım, ileri yöndeki taramada elde edilen akımdan küçük olduğundan, çukurcuk korozyonunun oluşmadığı anlaşılmaktadır.

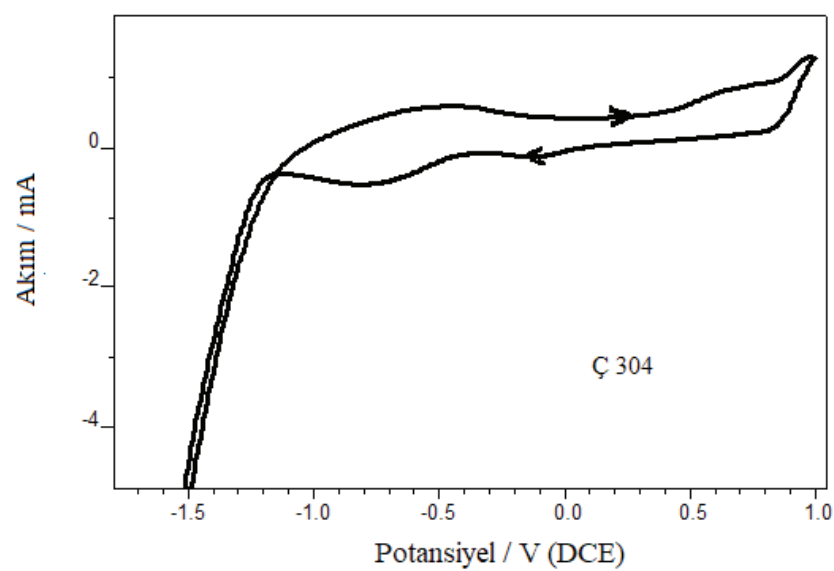

Şekil 2. Ç 304 çeliğin 0,100 M boraks içeren çözeltideki dönüşümlü voltamogram (Cyclic voltammogram of Ç 304 steel in solution containing $0.100 \mathrm{M}$ borax).

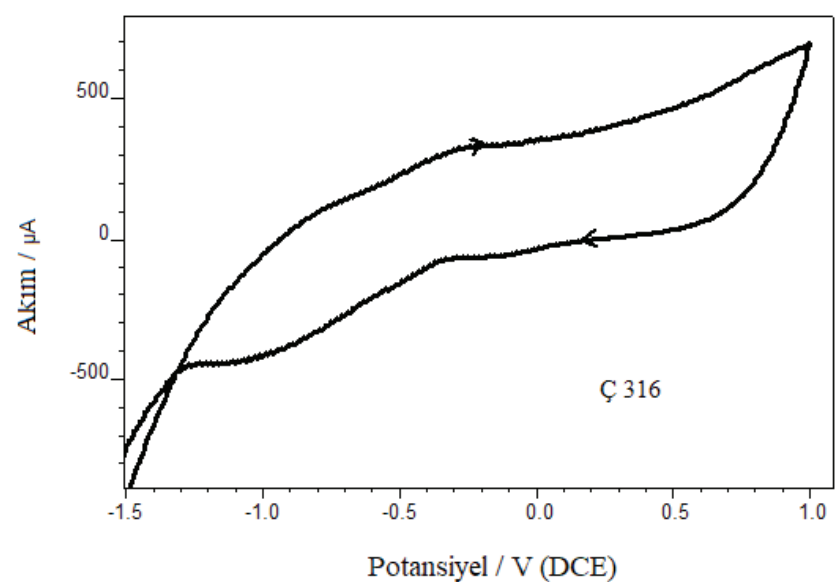

Şekil 3. Ç 316 çeliğin $0,100 \mathrm{M}$ boraks içeren çözeltideki dönüşümlü voltamogram (Cyclic voltammogram of Ç 316 steel in solution containing $0.100 \mathrm{M}$ borax).

Çeliklerin yükseltgenmesine karşı gösterilen direnci ifade eden polarizasyon direnci (Rp) her üç çelik için, boraks derişimin artması ile artış göstermiştir. Bu durum ölçülen korozyon hızının derişim artışıyla düşmesi sonucunu desteklemektedir. Korozyon hızı, Tafel polarizasyon metodu ile elde edilen eğrilerden anodik ve katodik eğrilerin eğim çizgilerin kesişmesi ile elde edilen akım yoğunluğunun bulunması ile belirlenmektedir [25]. Cihaza yüklü proğram, çeliklerin yoğunluğu ve eşdeğer gram ağırığının programa girilmesi ile belirlenen bu akım yoğunluğunu Faraday yasalarını kullanarak $\mathrm{mm} / \mathrm{yll}$ olarak hesaplayarak vermektedir.

Boraks derişiminin etkisini belirlemek amacıyla dört farklı boraks derişimde $(0,0125 \mathrm{M}, 0,025 \mathrm{M}, 0,050 \mathrm{M}$ ve $0,100 \mathrm{M})$ Ç 1010 çeliğinin korozyon hızı ölçüldü. Elde edilen Tafel polarizasyon eğriler Şekil 4'de çakıştırılmış haliyle verilmiştir. Bu eğrilerden elde edilen korozyon parametreleri Tablo 2'de özet olarak verilmiştir. Boraks derişiminin artmasıyla, korozyon potansiyeli daha pozitif değerlere kayarken, korozyon hızı düşmüştür. Korozyon hızı artan boraks derişimi ile sırasıyla $0,293,0,278,0,263$ ve $0,251 \mathrm{~mm} / \mathrm{y}$ Il olarak azalmıştır. Bu durum boraksın anodik bir inhibitör gibi davrandığını göstermektedir. Literatürde anodik inhibitör metal yüzeyinde bir film tabakası oluşturup pasifliği sağlayarak anodik reaksiyonu engelleyen kimyasal madde olarak tanımlanmaktadır. İnhibitör derişiminin artması ile korozyon hızında azalma ile birlikte korozyon potansiyelindeki pozitif artış anodik inhibitöre kanıt olarak gösterilmektedir $[26,27]$.

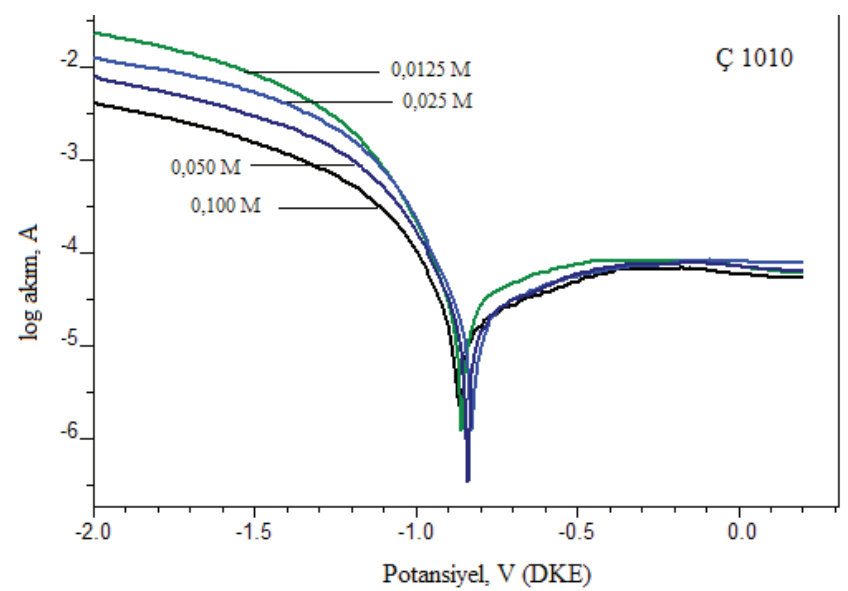

Şekil 4. Ç 1010 Çeliğin farklı boraks derişimi içeren çözeltilerde elde edilen Tafel Polarizasyon Eğrileri (Tafel Polarization Curves of C 1010 Steel in solutions with different borax concentrations).

Şekil 5'de Ç 304 çeliğin farklı boraks derişimlerde elde edilen Tafel Polarizasyon eğrilerinin çakıştııı ımış hali görülmektedir. Ç 304 çeliğinde anodik ve katodik dallar Ç 1010 çeliğine benzemekle beraber, korozyon akımı daha düşük ölçülmüştür. Korozyon hızı boraks derişimi ile azalma göstermiştir. Korozyon hızı artan derişimle sırasıyla, $0,162,0,145,0,138$ ve $0,132 \mathrm{~mm} / \mathrm{y} ı l$ olarak ölçülmüştür.

Şekil 6'da Ç 316 çeliğin dört farklı derişimdeki boraks çözeltisinde elde edilen çakıştırılmış Tafel polarizas- 
Tablo 2. Farklı boraks derişimlerinde çeliklerin korozyon parametreleri (Corrosion parameters of steels obtained in different borax concentrations).

\begin{tabular}{|c|c|c|c|c|c|c|}
\hline & $\begin{array}{c}\text { Boraks Derişimi (M) } \\
\text { (Borax Concentration (M)) }\end{array}$ & $\begin{array}{l}\text { Ecor } \\
\text { (V) }\end{array}$ & $\beta a$ & $\beta c$ & $\begin{array}{c}\mathrm{Rp} \\
\text { (ohm) }\end{array}$ & $\begin{array}{c}\text { Korozyon Hızı (mm/yıl) } \\
\text { (Corrosion Rate (mm/year)) }\end{array}$ \\
\hline \multirow{4}{*}{ Ç 1010} & 0,0125 & $-0,843$ & 0,458 & 0,198 & 1836 & 0,293 \\
\hline & 0,025 & $-0,836$ & 0,463 & 0,207 & 1849 & 0,278 \\
\hline & 0,050 & $-0,825$ & 0,476 & 0,212 & 1892 & 0263 \\
\hline & 0,100 & $-0,817$ & 0,487 & 0,223 & 1910 & 0,251 \\
\hline \multirow{4}{*}{ Ç 304} & 0,0125 & $-0,896$ & 0,602 & 0,205 & 3980 & 0,162 \\
\hline & 0,025 & $-0,888$ & 0,605 & 0,235 & 4209 & 0,145 \\
\hline & 0,050 & $-0,822$ & 0,612 & 0,242 & 4222 & 0,138 \\
\hline & 0,100 & $-0,813$ & 0,620 & 0,257 & 4241 & 0,132 \\
\hline \multirow{4}{*}{ Ç 316} & 0,0125 & $-0,905$ & 0,683 & 0,251 & 8452 & 0,090 \\
\hline & 0,025 & $-0,882$ & 0,698 & 0,263 & 8546 & 0,082 \\
\hline & 0,050 & $-0,852$ & 0,710 & 0,260 & 8651 & 0,079 \\
\hline & 0,100 & $-0,803$ & 0,729 & 0,263 & 9028 & 0,071 \\
\hline
\end{tabular}

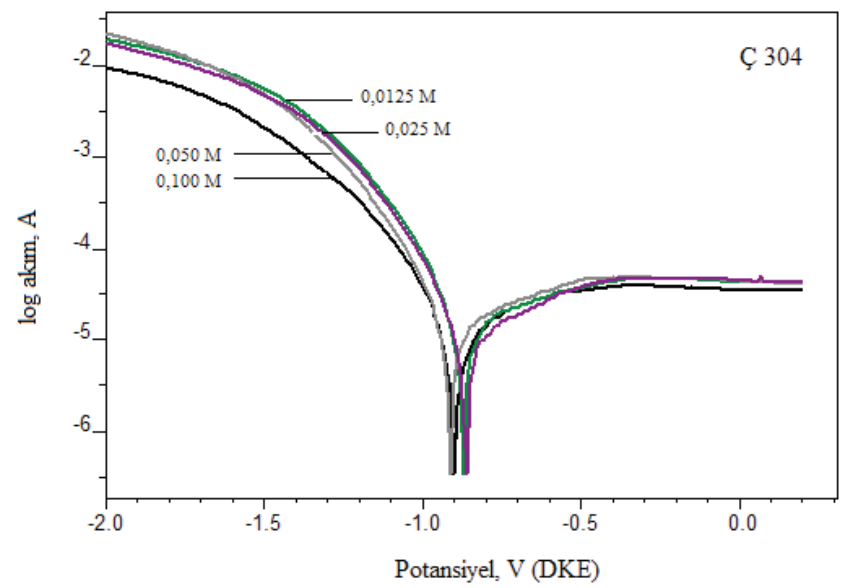

Şekil 5. Ç 304 Çeliğin farklı boraks derişimi içeren çözeltilerde elde edilen Tafel Polarizasyon Eğrileri (Tafel Polarization Curves of Ç 304 Steel in solutions with different borax concentrations).

yon eğrileri verilmektedir. Tüm çeliklerde, Tafel polarizasyon yöntemi ile elde edilen $\beta a, \beta c$ den oldukça yüksek çıkmıştır. Bu durum boraksın çeliği anodik olarak koruduğunun bir başka göstergesi olarak değerlendirilmektedir [18]. Korozyon hızında da önemli oranda azalma görülmektedir. Korozyon hızı 0,0125, 0,025, 0,050 ve $0,100 \mathrm{M}$ boraks derişimin artışı ile sırasıyla; 0,090, 0,082, 0,079 ve 0,071 olarak ölçülmüştür. Korozyon potansiyelinde, 0,1 M boraks çözeltinde $-0,803$ $\mathrm{V}$ değerine kadar anodik yönde artış olmuştur.

Şekil 7'de çalışılan en derişik ortam olan 0,100 M boraks çözeltisinde elde edilen, çeliklerin çakışık Tafel polarizasyon eğrileri verilmiştir. Çeliklerin genel olarak boraks çözeltilerinde oldukça korunaklı olduğu anlaşılmaktadır. Boraks çözeltilerinde korozyona karşı en iyi dayanım Ç 316 çeliğinde, daha sonra Ç 304 ve Ç 1010 da tespit edilmiştir. 0,100 M boraks çözeltisindeki korozyon hızları sırasıyla; 0,251, 0,132 ve 0,071 mm/yıl olarak ölçülmüştür. Ç 304 ve Ç 316 çeliklerin, Ç 1010 a göre daha korunaklı olması her iki çeliğin bileşiminde bulunan krom ve nikel alaşım elementinden kaynaklanmıştır. Ç 316 çeliğin Ç 304 çeliğinden daha dayanıklı olması ise Ç 316 bileşiminde bulunan

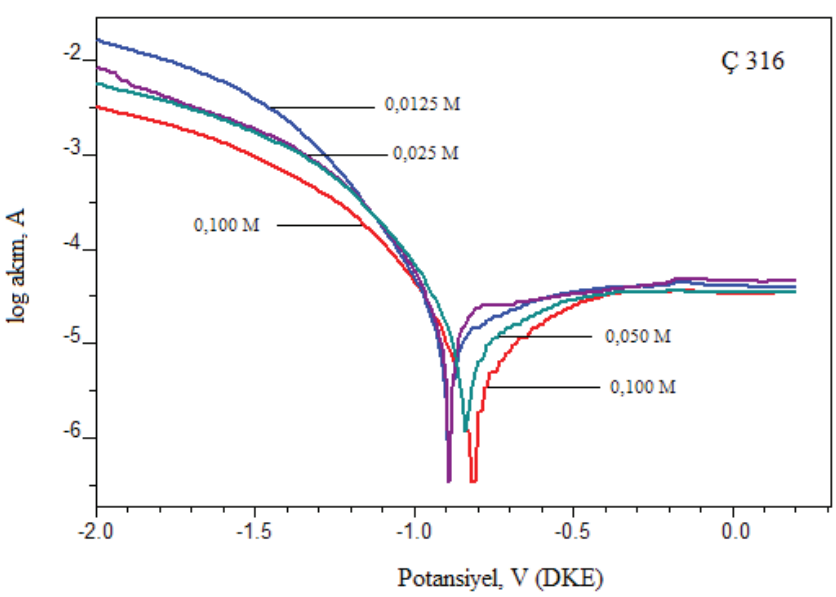

Şekil 6. Ç 316 Çeliğin farklı boraks derişimi içeren çözeltilerde elde edilen Tafel Polarizasyon Eğrileri (Tafel Polarization Curves of Ç 316 Steel in solutions with different borax concentrations).

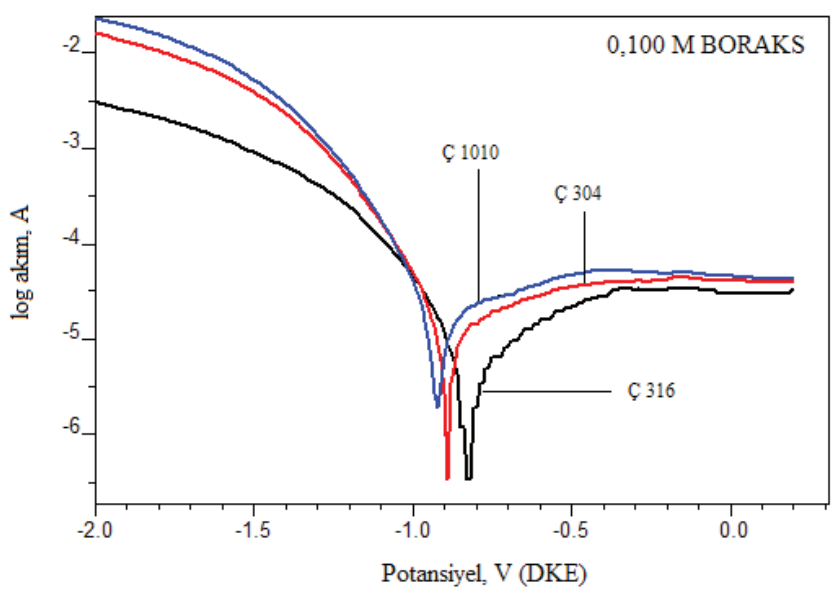

Şekil 7. Çeliklerin $0,100 \mathrm{M}$ boraks içeren çözeltilerde elde edilen Tafel Polarizasyon eğrileri (Tafel Polarization curves of steels obtained in solutions containing $0.100 \mathrm{M}$ borax). 
Mo alaşım elementinden kaynaklanmış olabilir. Ingle ve arkadaşları çalışmalarında, $316 \mathrm{~L}$ çeliği içine katılan Mo alaşım elementinin, çelik bileşimi içinde yer alan kromun pasifleştirme özelliğine katkı sağladığı ve çelik yüzeyindeki aktif bölgeleri önleyerek çeliği korozyondan koruduğu sonucuna vardılar [28].

Tablo 2 incelendiğinde, tüm verilerde Tafel anodik sabitinin ( $\beta a)$, Tafel katodik sabitinden ( $\beta c$ ) büyük olduğu görülmektedir. Bu durum korozyon mekanizmasının anodik reaksiyon kontrolünde olduğunu göstermektedir. Bu durum boraksın anodik inhibitör davranış gösterdiği tezini desteklemektedir [28].

Boraks derişiminin artması ile düşük karbonlu çeliklerde korozyon hızı azalmaktadır. En yüksek boraks derişime $(0,100 \mathrm{M})$ ile en düşük boraks derişime $(0,0125 \mathrm{M})$ sahip boraks çözeltilerde, Ç 1010 çeliğinde \%14,3, Ç 304 çeliğinde $\% 18,5$ ve Ç 316 çeliğinde $\% 21,1$ koruma sağlandığı anlaşımaktadır. Bu durum boraksın inhibitör olma potansiyeli olduğunu ve bu çeliklerin borakslı ortamlarda güvenle kullanılabileceğini göstermektedir.

\section{Sonuçlar (Conclusions)}

Sonuç olarak; borakslı çözeltilerde, Ç 1010, Ç 304 ve Ç 316 çelikleri korozyona karşı oldukça dirençlidir. Artan boraks derişimlerinde tüm çeliklerde korozyon hızı azalmıştır. Boraks, çeliklerde anodik inhibitör davranışı göstermiştir. Kimyasal bileşiminde bulundurduğu $\mathrm{Cr}$, $\mathrm{Ni}$ ve Mo alaşım elementleri sayesinde Ç 316 çeliği korozyona karşı en dayanıkı malzeme olarak tespit edilmiştir. Ç 1010 çeliği Ç 304 ve Ç 316 çeliklerine kıyasla daha düşük dayanım göstermekle birlikte, bu ortamda pasifleşme özelliği nedeniyle korozyona karşı direnç göstermiştir. Ç 304 çeliğin korozyona dayanımı Ç 316 dan düşük, Ç 1010 çeliğinden yüksek olarak bulunmuştur.

\section{Kaynaklar (References)}

[1] Perumal, K. E. (2014). Corrosion risk analysis, riskbased inspection and a case study concerning a condensate pipeline. Procedia Engineering, 86, 597-605.

[2] Loto, R. T. \& Oluwatobilola, O. (2018). Corrosion inhibition properties of the combined admixture of essential oil extracts on mild steel in the presence of SO4 anions, South African Journal of Chemical Engineering, $26,35-41$.

[3] David, A.W.(2017). Predicting the performance of organic corrosion inhibitors. Metals, 7(12), 553-559.

[4] Yilmaz, A. E. Boncukcuoǧlu, R., Kocakerm, M. M., \& Kocadağistan, E. (2008). An empirical model for kinetics of boron removal from boroncontaining wastewaters by the electrocoagulation method in a batch reactor. Desalination, 230(1-3), 288-297.

[5] Abu-Hamed, T., Karni, J., \& Epstein, M. (2007). The use of boron for thermochemical storage and distribution of solar energy. Solar Energy, 81(1), 93-101.
[6] Obut, A., Ehsani, İ., Aktosun, Z., Yörükoğlu, A., Girgin, I., \& Temel, A. (2020). Leaching behaviour of lithium from a clay sample of Kırka borate deposit in sulfuric acid solutions. Journal of Boron, 5(4), 170-175.

[7] Ezechi, E. H., Isa, M. H., Kutty, S. R., \& Sapari, N. B. (2011, September). Boron recovery, application and economic significance: A review. In 2011 National Postgraduate Conference (pp. 1-6). IEEE.

[8] Doğan, F., Duru E., Uysal,M., Akbulut, H. \& Arslan, S. (2021). Investigation of mechanical and tribological characteristics of Ni-B coatings deposited on steel. Journal of Boron, 6(1), 209-215.

[9] Mohana, K.N. \& Badiea, A.M. (2008). Effect of sodium nitrite-borax blend on the corrosion rate of low carbon steel in industrial water medium. Corrosion Science, 50(10), 2939-2947.

[10] Graham, M. J., Bardwell, J. A., Sproule, G. I., Mitchell, D. F., \& MacDougall, B. R. (1993). The growth and stability of passive films. Corrosion Science, 35(1-4), 13-18.

[11] Sılku, P., Özkinalı, S., Öztürk, Z., Asan, A., \& Köse, D.A. (2016). Synthesis of novel Schiff Bases containing acryloyl moiety and the investigation of spectroscopic and electrochemical properties. Journal of Molecular Structure, 1116, 72-83.

[12] Tran, M., Mohammedi, D., Fiaud, C., \& Sutter, E. M. M. (2006). Corrosion behaviour of steel in the presence of Y(III) salts: Kinetic and mechanistic studies. Corrosion Science, 48(12), 4257-4273.

[13] Igual Muñoz, A., García Antón, J., Guiñón, J. L., \& Pérez Herranz, V. (2006). The effect of chromate in the corrosion behavior of duplex stainless steel in $\mathrm{LiBr}$ solutions. Corrosion Science, 48(12), 4127-4151.

[14] Bethencourt, M., Botana, F. J., Calvino, J. J., Marcos, M., \& Rodríguez-Chacón, M. A. (1998). Lanthanide compounds as environmentally-friendly corrosion inhibitors of aluminium alloys: A review. Corrosion Science, 40(11), 1803-1819.

[15] Sruthi, R., Rampradheep, G. S., \& Raja, K. (2020). A review on natural plant extract as a green inhibitor for steel corrosion resistance. International Journal of Advanced Science and Technology, 29(3), 3529-3550.

[16] Paul, S., \& Koley, I. (2016). Corrosion inhibition of carbon steel in acidic environment by papayaseed as green inhibitor. Journal of Bio-and Tribo-Corrosion, 2(2) $1-9$

[17] Abbas, A. S., Fazakas, É., \& Török, T. I. (2018). Corrosion studies of steel rebar samples in neutral sodium chloride solution also in the presence of a bio-based (green) inhibitor. International Journal of Corrosion and Scale Inhibition, 7(1), 38-47.

[18] Bakirhan, N. K., Asan, A., Colak, N., \& Sanli, S. (2016). The inhibition of steel corrosion in acidic solutions by a new Schiff base. Journal of the Chilean Chemical Society, 61(3), 3066-3070 .

[19] Olefjord, I., \& Clayton, C. R. (1991). Surface composition of stainless steel during active dissolution and passivation. ISIJ International, 31(2), 134-141.

[20] Alibakhshi, E., Ramezanzadeh, M. Bahlakeh, G., 
Ramezanzadeh, B., Mahdavian, M., \& Motamedi, M. (2018). Glycyrrhiza glabra leaves extract as a green corrosion inhibitor for mild steel in $1 \mathrm{M}$ hydrochloric acid solution: Experimental, molecular dynamics, Monte Carlo and quantum mechanics study. Journal of Molecular Liquids, 255, 185-198.

[21] Salhi, A., Tighadouini, S., El-Massaoudi, M., Elbelghiti, M., Bouyanzer, A., Radi, S., ... \& Zarrouk, A. (2017). Keto-enol heterocycles as new compounds of corrosion inhibitors for carbon steel in $1 \mathrm{M} \mathrm{HCl}$ : weight loss, electrochemical and quantum chemical investigation. Journal of Molecular Liquids, 248, 340-349.

[22] McCafferty, E. (2005). Validation of corrosion rates measured by the Tafel extrapolation method. Corrosion Science, 47(12), 3202-3215.

[23] Pardo, A., Merino, M. C., Coy, A. E., Viejo, F., Arrabal, R., \& Matykina, E. (2008). Pitting corrosion behaviour of austenitic stainless steels - combining effects of $\mathrm{Mn}$ and Mo additions. Corrosion Science, 50(6), 17961806.

[24] Olsson, C. O. A., \& Landolt, D. (2003). Passive films on stainless steels - Chemistry, structure and growth. Electrochimica Acta, 48(9), 1093-1104.

[25] Mansfeld, F. (1973). Tafel slopes and corrosion rates from polarization resistance measurement. Corrosion, 29(10), 397-402.

[26] Oguzie, E. E., Li, Y., \& Wang, F. H. (2007). Corrosion inhibition and adsorption behavior of methionine on mild steel in sulfuric acid and synergistic effect of iodide ion. Journal of Colloid and Interface Science, 310(1), 90-98.

[27] Aliofkhazraei, M. (Ed.). (2014). Devolepments in Corrosion Protection. Intech Open. ISBN: 978-953-516359-6.

[28] Ingle, A. V., Raja, V.S., Mishra, P., \& Rangarajan, J.(2020). Effect of Mo Addition on the corrosion behavior of $\mathrm{Al}-40 \mathrm{Cr}-\mathrm{xMo}$ coatings on type $316 \mathrm{~L}$ stainless steel. Metallurgical and Materials Transactions A: Physical Metallurgy and Materials Science, 51(4), 1933-1944. 